\section{Check for updates}

Cite this: Mater. Adv., 2021, 2, 6665

Received 17th July 2021 Accepted 26th August 2021

DOI: $10.1039 / \mathrm{d} 1 \mathrm{ma} 00619 \mathrm{c}$

rsc.li/materials-advances

\title{
Melt-quenched vanadium pentoxide-stabilized chitosan nanohybrids for efficient hydrazine detection
}

\begin{abstract}
Jay Singh, (D)*a Kshitij RB Singh, (D) ${ }^{\mathrm{b}}$ Manish Kumar, ${ }^{\mathrm{c}}$ Rahul Verma, ${ }^{a}$ Ranjana Verma, ${ }^{\mathrm{d}}$ Priya Malik, ${ }^{c}$ Saurabh Srivastava, ${ }^{e}$ Ravindra Pratap Singh (D) ${ }^{f}$ and Devendra Kumar*c

Nanocrystalline low-dimensional nanostructured vanadium pentoxide $\left(n-\mathrm{V}_{2} \mathrm{O}_{5}\right)$ nanoparticles were synthesized using a hydrothermal and melt-quenching approach without using any reducing agent, acids/bases, and hazardous solvents. Further, the synthesized $\mathrm{V}_{2} \mathrm{O}_{5}$ nanoparticles were successfully dispersed in a chitosan (CS) solution for fabricating an organic-inorganic nanohybrid matrix for the electrocatalytic determination of hydrazine to avoid human exposure. Furthermore, this study was supported by various sophisticated tools to characterize the synthesized $\mathrm{V}_{2} \mathrm{O}_{5}$ and $\mathrm{V}_{2} \mathrm{O}_{5}-\mathrm{CS}$ films, namely UV-Vis, PL, FTIR, XRD, SEM, AFM, TEM, and EDX. The $\mathrm{V}_{2} \mathrm{O}_{5}-\mathrm{CS}$ nanohybrid showed a substantial sensing strength when deposited onto an indium-tin-oxide (ITO)-coated glass substrate without ultrasonication and studied using amperometry and cyclic voltammetry techniques. Thus, the electrochemical responses against various hydrazine concentrations obtained from the fabricated $\mathrm{V}_{2} \mathrm{O}_{5}-\mathrm{CS} / \mathrm{ITO}$ electrode demonstrated high sensitivity, a low detection limit, a quick response time, and a wide linear range of $50.48 \mu \mathrm{A} \mu \mathrm{M}^{-1} \mathrm{~cm}^{-2}, 0.084 \mathrm{mM}, 20$ seconds, and 2-22 $\mathrm{mM}$ at a $50 \mathrm{mV}$ scan rate, respectively. Hence, the utilization of $\mathrm{V}_{2} \mathrm{O}_{5}-\mathrm{CS}$-based inorganic-organic nanohybrid materials fabricates a robust sensing system and a favorable sensing platform with wide applications towards the development of electrochemical sensor devices.
\end{abstract}

\section{Introduction}

Hydrazine has demonstrated enormous applications as a pesticide, blowing agent, propellant, insecticide, antioxidant, plant-growth regulator, pharmaceutical intermediate, and corrosion inhibitor. ${ }^{1-3}$ However, despite its applications, it shows toxicity and acts as a cancer-causing, nephrotoxic material, causing damage to the nervous system and genetic material. ${ }^{4-8}$ For overcoming these issues, the fast, selective, and efficient electrocatalytic detection of hydrazine is necessary to help avoid human exposure, as, in the environment,

\footnotetext{
${ }^{a}$ Department of Chemistry, Institute of Science, Banaras Hindu University, Varanasi, Uttar Pradesh, India. E-mail: jaimnnit@gmail.com

${ }^{b}$ Department of Chemistry, Govt. V. Y. T. PG Autonomous College, Durg, Chhattisgarh, India

${ }^{c}$ Department of Applied Chemistry \& Polymer Technology, Delhi Technological University, Shahbad Daulatpur, Main Bawana Road, Delhi, India. E-mail: dkumar@dce.ac.in

${ }^{d}$ Department of Physics, Institute of Science, Banaras Hindu University, Varanasi, Uttar Pradesh, India

${ }^{e}$ Department of Applied Science \& Humanities, Rajkiya Engineering College Ambedkar Nagar, Dr. A.P.J. Abdul Kalam Technical University, Uttar Pradesh, India

${ }^{f}$ Department of Biotechnology, Indira Gandhi National Tribal University, Amarkantak, Madhya Pradesh, India
}

hydrazine decomposes very rapidly and does not harm humankind through environmental factors, but when hydrazine is used in agriculture as a pesticide its overuse can lead to uptake by plants/crops, which when consumed by animals and humans can lead to various life-threatening complications like cancer, neurological disorders, etc. ${ }^{9-12}$ Furthermore, several studies reported in this context for hydrazine sensing centered on various electro-oxidation methods of hydrazine are based on nanostructured materials and polymer nanocomposites. ${ }^{13-17}$ However, these electrochemical sensors have many drawbacks because of a lack of surface architectures that give an electrochemical sensor a higher sensitivity and specificity against analytes of interest by utilizing nanostructured materials - thus miniaturizing the elements of the sensor and increasing the signal-to-noise ratio at the device interface - and, so far, many nanomaterials with a variable morphology have been used for fabricating electro-oxidation platforms. ${ }^{18-25}$

Moreover, owing to the multiple valence states and the maximum oxidation state of vanadium, nanostructured $\mathrm{V}_{2} \mathrm{O}_{5}$ exhibits enhanced catalytic properties, high electron-transfer kinetics, and an enhanced adsorption capability for chargetransfer characteristics. Therefore, vanadium pentoxide nanostructures $\left(\mathrm{n}-\mathrm{V}_{2} \mathrm{O}_{5}\right)$ are promising materialsshowing a high chemical stability and enhanced catalytic activity. ${ }^{19,26-29}$ 


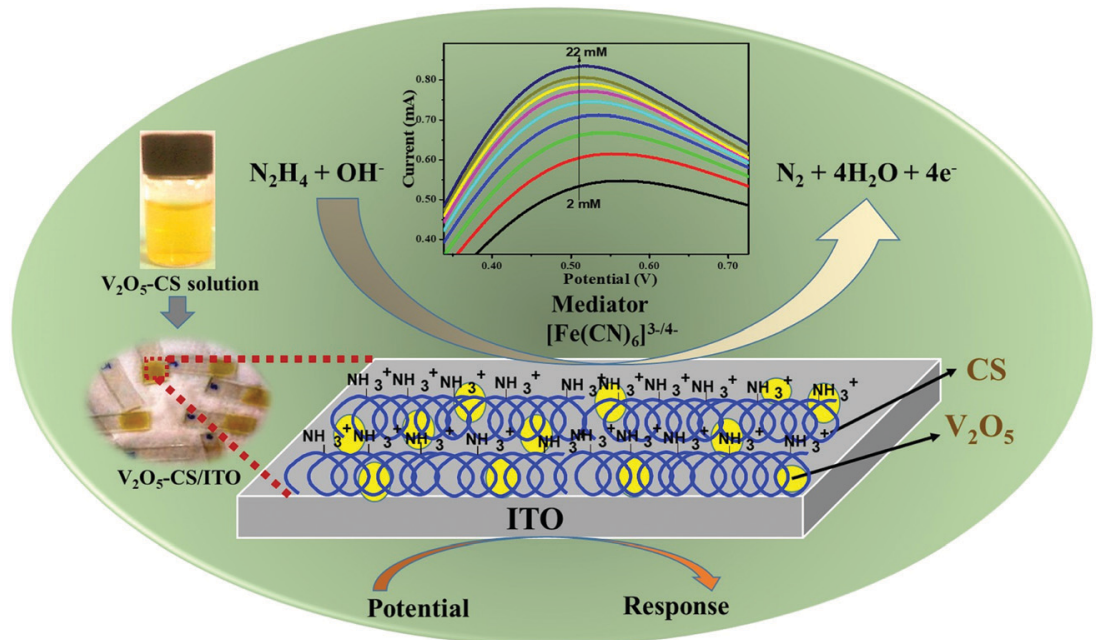

Fig. 1 Schematic overview of this works.

Furthermore, chitosan (CS) is a non-toxic biopolymer that exhibits high biocompatibility and film-forming abilities. Many studies ${ }^{30,31}$ to date have shown that CS is a promising material for synthesizing nanocomposites with various metal and metal oxide nanoparticles, which will offer nanocomposites with extraordinary properties. Thus, here in this study, CS is used to form a nanocomposite with the metal $\left(\mathrm{n}-\mathrm{V}_{2} \mathrm{O}_{5}\right)$ due to its film-forming ability and stability to control aggregation, which will stabilize the $\mathrm{n}-\mathrm{V}_{2} \mathrm{O}_{5}$ film on the electrode surface. ${ }^{32,33}$ The $\mathrm{V}_{2} \mathrm{O}_{5}-\mathrm{CS}$ inorganic $\left(\mathrm{V}_{2} \mathrm{O}_{5}\right)$-organic (CS) nanostructured hybrid film was developed for the effective and efficient electrochemical determination of hydrazine in an aqueous solution, and the film was prepared via a simple solution-casting method of this nanohybrid onto an ITO-coated glass substrate, which demonstrated an excellent film-forming ability, charge-transfer characteristics, a large surface area, and a high adsorption capability. Thus, we investigated the fabricated electrochemical device via the smart and intelligent $\mathrm{V}_{2} \mathrm{O}_{5}-\mathrm{CS}$ nanohybrid to monitor hydrazine to avoid human exposure (Fig. 1). Hence, in this work, the used nanocomposite was synthesized using the melt-quenched and hydrothermally derived nanocrystalline $\mathrm{V}_{2} \mathrm{O}_{5}\left(\mathrm{n}-\mathrm{V}_{2} \mathrm{O}_{5}\right)$ ex situ grafted onto the chitosan (CS) biopolymer as an organic-inorganic nanohybrid material without the use of any reducing agent, acids/bases, and hazardous solvents for the determination of hydrazine; this makes our synthesis procedure unique compared with other pre-existing synthesis methods such as in situ and various other ex situ protocols.

\section{Experimental section}

\subsection{Materials}

Vanadium pentoxide $\left(\mathrm{V}_{2} \mathrm{O}_{5} ;\right.$ molecular weight $\left(M_{\mathrm{W}}\right)$ : $181.88 \mathrm{~g} \mathrm{~mol}^{-1}$; CAS number: 1314-62-1), hydrogen peroxide $\left(\mathrm{H}_{2} \mathrm{O}_{2} ; M_{\mathrm{W}}: 34 \mathrm{~g} \mathrm{~mol}^{-1}\right.$; Product Cat no. 1.93007.0521), chitosan (CAS number: 9012-76-4), potassium hexacyanoferrate(II) trihydrate $\left(\mathrm{C}_{6} \mathrm{FeK}_{4} \mathrm{~N}_{6} \cdot 3 \mathrm{H}_{2} \mathrm{O} ; M_{\mathrm{W}}: 422.39 \mathrm{~g} \mathrm{~mol}^{-1}\right.$; product cat no.: 1.93686.0521), potassium hexacyanoferrate(III) $\left(\mathrm{C}_{6} \mathrm{FeK}_{3} \mathrm{~N}_{6} ; M_{\mathrm{W}}\right.$ :
$329.25 \mathrm{~g} \mathrm{~mol}^{-1}$; product cat no.: 1.93667.0521), glacial acetic acid $\left(\mathrm{CH}_{3} \mathrm{CO}_{2} \mathrm{H} ; M_{\mathrm{W}}\right.$ : 60.05; CAS number: 64-19-7), sodium chloride $\left(\mathrm{NaCl} ; M_{\mathrm{W}}: 58.44 \mathrm{~g} \mathrm{~mol}^{-1}\right.$; Product Cat no. S9888) and hydrazine solution $\left(\mathrm{NH}_{2} \mathrm{NH}_{2} ; M_{\mathrm{W}}\right.$ : 32.05; CAS number: 30201-2) were obtained from Sigma-Aldrich. Sodium hydroxide $\left(\mathrm{NaOH} ; M_{\mathrm{W}}: 40.00 \mathrm{~g} \mathrm{~mol}^{-1}\right.$; CAS no. 1310-73-2), acetone $\left(\mathrm{C}_{3} \mathrm{H}_{6} \mathrm{O} ; M_{\mathrm{W}}\right.$ : 58.08; CAS number: 67-64-1), and ammonia solution $\left(\mathrm{NH}_{3} ; M_{\mathrm{W}}: 17.03 \mathrm{~g} \mathrm{~mol}^{-1}\right.$; CAS no. Q16225) were obtained from Qualigens, Thermo Fisher Scientific. Disodium phosphate $\left(\mathrm{Na}_{2} \mathrm{HPO}_{4} \cdot \mathrm{H}_{2} \mathrm{O} ; M_{\mathrm{W}}: 177.99\right.$; CAS no. 10028-24-7) and monosodium phosphate $\left(\mathrm{NaH}_{2} \mathrm{PO}_{4} ; M_{\mathrm{W}}\right.$ : 119.98; CAS no. 7558-80-7) were procured from Himedia. All the chemicals used for the experiments were of analytical grade, and they were used as received without further purification. The ITO sheets (surface resistivity $\sim 15 \Omega \mathrm{cm}^{-1}$ ) for deposition of the $\mathrm{V}_{2} \mathrm{O}_{5}-\mathrm{CS}$ nanohybrid were procured from Sigma-Aldrich. Milli-Q water (18 $\Omega$ resistivity), Millipore, USA, was used to perform all the experimental works, and the stock solution of hydrazine was prepared in $5 \mathrm{mM}$ phosphate buffer of $\mathrm{pH}$ 6.4.

\section{2. $\quad n-V_{2} O_{5}$ nanoparticle synthesis}

The $\mathrm{V}_{2} \mathrm{O}_{5}$ nanoparticles were synthesized via hydrothermal and melt-quenching methods, as reported previously ${ }^{34}$ with some modifications. First, as purchased, micro-size $\mathrm{V}_{2} \mathrm{O}_{5}(5 \mathrm{~g})$ powder was weighed and kept in a crucible, which was placed in a muffle furnace at $900{ }^{\circ} \mathrm{C}$ until the molten phase was achieved; it was then taken out and cooled to room temperature using cold Milli-Q water with continuous stirring for eight hours until the $\mathrm{V}_{2} \mathrm{O}_{5}$ sol was finally obtained, and this sol was kept overnight in a sealed airtight bottle for aging before it was transferred to a Teflon-lined stainless steel hydrothermal vessel. Next, this vessel was placed in a hot air oven for 15 hours at $180{ }^{\circ} \mathrm{C}$ before being allowed to cool by natural convection to room temperature. Subsequently, a yellow residue was obtained, which was washed several times with Milli-Q water and, lastly, it was washed with ethanol to remove any impurities before being vacuum dried at $50{ }^{\circ} \mathrm{C}$. 


\section{3. $\quad \mathrm{V}_{2} \mathrm{O}_{5}$ nanoparticle electrophoretic deposition (EPD)}

EPD was performed using a BioRad, Model 200/0.2 instrument (DC power supply unit). Before EPD, $\mathrm{V}_{2} \mathrm{O}_{5}$ nanoparticles $(20 \mathrm{mg}$ ) were sonicated in $10 \mathrm{~mL}$ of absolute ethanol for one hour using an ice bath to avoid alcohol evaporation. After that, a yellow and opaque suspension of $\mathrm{V}_{2} \mathrm{O}_{5}$ nanoparticles was obtained. Then, this as-prepared colloidal suspension of $\mathrm{V}_{2} \mathrm{O}_{5}$ nanoparticles was transferred to a two-electrode-based electrochemical cell. A platinum electrode was used as the anode and the hydrolyzed ITO-coated glass substrate acted the cathode, where the anode and cathode were parallel to each other and had a separation distance of $1 \mathrm{~cm}$. This setup resulted in the formation of a thin, uniform, and homogeneous $\mathrm{V}_{2} \mathrm{O}_{5}$ film on ITO $\left(0.25 \mathrm{~cm}^{2}\right)$ via EPD using the optimal conditions of $25 \mathrm{~V}$ for 15 seconds. Moreover, this prepared $\mathrm{V}_{2} \mathrm{O}_{5} / \mathrm{ITO}$ film electrode was washed several times with Milli-Q water followed by ethanol for removing any unbound particles; it was stored at $4{ }^{\circ} \mathrm{C}$ for further experiments.

\section{4. $\mathrm{V}_{2} \mathrm{O}_{5}-\mathrm{CS} / \mathrm{ITO}$ nanohybrid film fabrication}

$\mathrm{V}_{2} \mathrm{O}_{5}$ nanoparticles (30 mg) were dispersed in a CS solution $(1 \mathrm{wt} \% ; 5 \mathrm{~mL})$ and were kept under ultrasonication for two hours, which resulted in a highly viscous solution of CS with $\mathrm{V}_{2} \mathrm{O}_{5}$ nanoparticles dispersed uniformly. Then from this viscous solution, a $10 \mu \mathrm{L}$ sample was aliquoted onto a pre-cleaned ITO-coated glass substrate $\left(0.25 \mathrm{~cm}^{2}\right)$ to form a thin film of the $\mathrm{V}_{2} \mathrm{O}_{5}$-CS composite via the drop-casting method; this was then allowed to dry at room temperature. After drying, the thin-film composite was washed using Milli-Q water to remove any unbound particles. Furthermore, the prepared $\mathrm{V}_{2} \mathrm{O}_{5}-\mathrm{CS} / \mathrm{ITO}$ electrode was used for performing electro-oxidation studies of hydrazine using the three-electrode system.

\subsection{Characterization}

Several characterization techniques were used to study the asprepared $\mathrm{V}_{2} \mathrm{O}_{5}, \mathrm{~V}_{2} \mathrm{O}_{5} / \mathrm{ITO}, \mathrm{V}_{2} \mathrm{O}_{5}-\mathrm{CS}$, and $\mathrm{V}_{2} \mathrm{O}_{5}-\mathrm{CS} / \mathrm{ITO}$ samples. Initially, the ultraviolet-visible (UV-vis) spectra were obtained in the wavelength range of 200-800 nm using a PerkinElmer, Lambda 950 spectrophotometer. Then, the vibration spectra were obtained using a Fourier transform infrared (FTIR) spectrophotometer (Nicolet 380, Thermo Fisher Scientific) in the 400-4000 $\mathrm{cm}^{-1}$ wavenumber range. X-Ray diffraction measurements were carried out using a D8 Advance, Bruker, with $\mathrm{Cu}-\mathrm{K} \alpha$ $(\lambda=1.5406 \AA)$ radiation and a Ni filter in the $2 \theta$ angle range of 10-50 . Thermogravimetric (TGA) analysis was performed using a Model-STA 6000 instrument (PerkinElmer, Singapore). Photoluminescence (PL) spectra were obtained utilizing a Fluoro$\log ^{\circledR}-3$ spectrofluorometer (Horiba). The energy dispersive $\mathrm{X}$-ray (EDX) and scanning electron microscope (SEM) analyses were performed using a Hitachi S-3700N instrument for elemental confirmation and surface morphology analysis of the as-prepared nanoparticles and nanohybrids. In addition, atomic force microscopy (AFM) (Park Systems, XE 100) was also utilized for determining the surface morphologies of the $\mathrm{V}_{2} \mathrm{O}_{5}$ / ITO and $\mathrm{V}_{2} \mathrm{O}_{5}-\mathrm{CS} / \mathrm{ITO}$ electrodes. Moreover, selected area electron diffraction pattern (SAED) and high-resolution transmission electron microscopy (HR-TEM) micrographs were obtained utilizing an FEI Tecnai G2 F20-Twin, Swiss Confederation instrument. Finally, an Autolab PG workstation, Metrohm, was utilized for performing electro-oxidation studies of
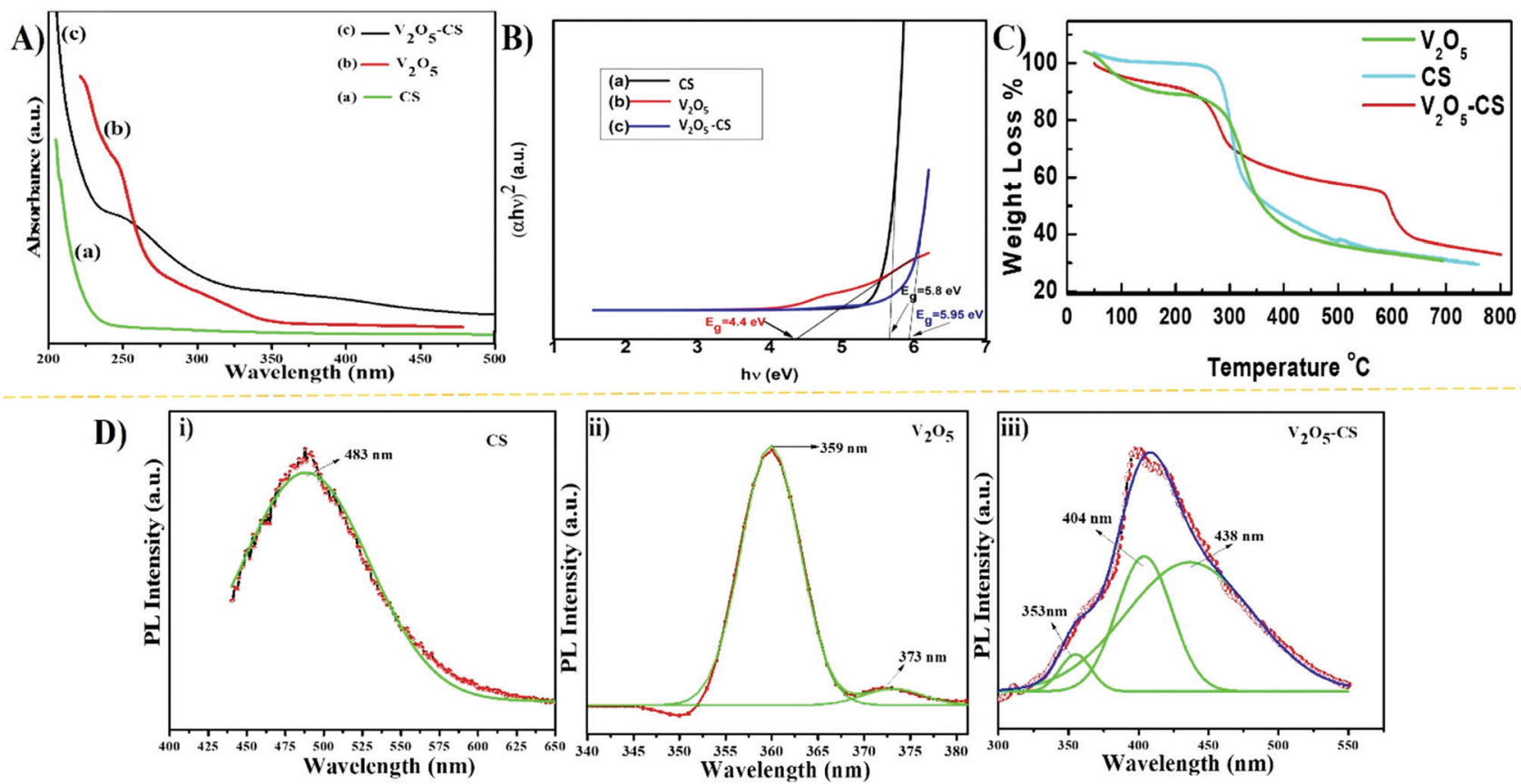

Fig. 2 (A) UV-vis absorption spectra, (B) band gaps in terms of the Tauc plot of $(\alpha h \nu)^{2}$ versus (hv), (C) TGA analysis, and (D) photoluminescence spectra for (i) $\mathrm{CS}$, (ii) $\mathrm{V}_{2} \mathrm{O}_{5}$ nanoparticles, and (iii) $\mathrm{V}_{2} \mathrm{O}_{5}-\mathrm{CS}$ nanohybrid. 
hydrazine via the $\mathrm{V}_{2} \mathrm{O}_{5}-\mathrm{CS} / \mathrm{ITO}$ electrode using the threeelectrode system, in which a platinum wire was used as the counter electrode, $\mathrm{V}_{2} \mathrm{O}_{5}-\mathrm{CS} / \mathrm{ITO}$ was the working electrode, and $\mathrm{Ag} / \mathrm{AgCl}$ was the reference electrode in the presence of a mediator of $5 \mathrm{mM}\left[\mathrm{Fe}(\mathrm{CN})_{6}\right]^{3-/ 4-}$ in $50 \mathrm{mM}$ phosphate buffer saline (PBS) at $\mathrm{pH} 6.4$ containing $0.9 \% \mathrm{NaCl}$.

\section{Results and discussion}

\subsection{Structural, optical, and morphological characterization of $\mathrm{V}_{2} \mathrm{O}_{5}, \mathrm{~V}_{2} \mathrm{O}_{5}-\mathrm{CS}$, and $\mathrm{V}_{2} \mathrm{O}_{5}-\mathrm{CS} / \mathrm{ITO}$}

The CS, $\mathrm{V}_{2} \mathrm{O}_{5}$ nanoparticles and $\mathrm{V}_{2} \mathrm{O}_{5}-\mathrm{CS}$ nanohybrid were initially studied utilizing the UV-vis spectrum, recorded in the 200-500 nm range (Fig. 2(A)). As CS is transparent in the ultraviolet and visible regions thus, determining its optical properties using spectroscopic methods is very difficult. For the $\mathrm{V}_{2} \mathrm{O}_{5}$ nanoparticles, the $\mathrm{UV}$-vis spectrum demonstrates two absorption peaks at 248 and $208 \mathrm{~nm}$, while the broad peak that arises at $242 \mathrm{~nm}$ in the $\mathrm{V}_{2} \mathrm{O}_{5}-\mathrm{CS}$ nanohybrid is due to the combination of $\pi-\pi^{*}$ transitions and $n-\pi^{*}$ transitions. Furthermore, the optical band gap was calculated using the Tauc plot by plotting $(\alpha h \nu)^{2}$ vs. $h \nu(\mathrm{eV})$, as shown in Fig. 2(B). By extrapolating the linear part to the energy axis, the energy band gap $\left(E_{\mathrm{g}}\right)$ values obtained are 5.8, 4.4, and $5.95 \mathrm{eV}$ for $\mathrm{CS}$, the $\mathrm{V}_{2} \mathrm{O}_{5}$ nanoparticles and the $\mathrm{V}_{2} \mathrm{O}_{5}-\mathrm{CS}$ nanohybrid, respectively. Compared with the $\mathrm{V}_{2} \mathrm{O}_{5}$ nanoparticles, the increase in the band gap of the $\mathrm{V}_{2} \mathrm{O}_{5}-\mathrm{CS}$ nanohybrid is due to the $\mathrm{V}_{2} \mathrm{O}_{5}$ nanoparticles being successfully intercalated into the CS matrix. The reason behind the increase in the band gap of the nanohybrid is that in $\mathrm{CS}$ in the acidic solution phase, the $\mathrm{NH}_{2}$ group of $\mathrm{CS}$ is protonated to acquire a positive charge $\left(\mathrm{NH}_{3}{ }^{+}\right)$, which offers the CS a slightly higher band gap of $5.8 \mathrm{eV}$, and when CS was crafted with the $\mathrm{V}_{2} \mathrm{O}_{5}$ nanoparticles to form the $\mathrm{V}_{2} \mathrm{O}_{5}-\mathrm{CS}$ nanohybrid the conduction band of the nanohybrid increased, becoming $5.95 \mathrm{eV}$ due to the favorable environment provided by the CS, which suppresses the conduction band of $\mathrm{V}_{2} \mathrm{O}_{5}$ and offers the nanohybrid an elevated band gap. Furthermore, the thermal behaviour of $\mathrm{CS}, \mathrm{V}_{2} \mathrm{O}_{5}$ and $\mathrm{V}_{2} \mathrm{O}_{5}-\mathrm{CS}$ nanohybrid was studied using TGA in the temperature range from 30 to $800{ }^{\circ} \mathrm{C}$. The initial weight loss of CS in the temperature range of 50-140 ${ }^{\circ} \mathrm{C}$ is about $16 \%$ [Fig. 2(C) (cyan color)], which might be due to the loss of residual moisture in the sample. CS shows a slight weight loss between 140 and $250{ }^{\circ} \mathrm{C}$ owing to the decomposition of small chain polymers, followed by a more apparent loss of weight starting from 250 up to $485{ }^{\circ} \mathrm{C}$, which might be ascribed to a multifaceted process including dehydration of the saccharide units in the polymer. ${ }^{35,36}$ On the other hand, in the TGA curve for the $\mathrm{V}_{2} \mathrm{O}_{5}-\mathrm{CS}$ nanohybrid [Fig. 2(C) (red color)] up to $225{ }^{\circ} \mathrm{C}$, the weight loss of the nanohybrid film is quite small (up to $11 \%$ ) because of the removal of the absorbed physical and chemical moisture content. When the temperature was increased to higher than $550{ }^{\circ} \mathrm{C}$, the weight loss of up to $45 \%$ was significant because CS was decomposed into smaller units. The TGA curve of $\mathrm{V}_{2} \mathrm{O}_{5}$ nanoparticles [Fig. 2(C) (green color)] shows that the weight loss in the temperature range of about $30-140{ }^{\circ} \mathrm{C}$ is due to the removal of water in the sample. ${ }^{37}$ Moreover, the $\mathrm{V}_{2} \mathrm{O}_{5}$ nanoparticles exhibit a significant weight loss of up to $65 \%$ when the temperature is increased to $460{ }^{\circ} \mathrm{C}$. Therefore, although the prepared $\mathrm{V}_{2} \mathrm{O}_{5}-\mathrm{CS}$ nanohybrid exhibits a higher thermal stability than CS and the $\mathrm{V}_{2} \mathrm{O}_{5}$ nanoparticles, there was no considerable weight change from $645{ }^{\circ} \mathrm{C}$ to $800{ }^{\circ} \mathrm{C}$, implying the presence of only $\mathrm{V}_{2} \mathrm{O}_{5}$ within the temperature range. Fig. 2(D) shows the PL spectra of CS, $\mathrm{V}_{2} \mathrm{O}_{5}$ nanoparticles and the $\mathrm{V}_{2} \mathrm{O}_{5}-\mathrm{CS}$ nanohybrid performed at the $420 \mathrm{~nm}$ excitation wavelength. The emission spectra show peaks at $483 \mathrm{~nm}$ (Fig. 2(D)(i)), $359 \mathrm{~nm}$ (Fig. 2(D)(ii)), and $404 \mathrm{~nm}$ Fig. 2(D)(iii) for $\mathrm{CS}, \mathrm{V}_{2} \mathrm{O}_{5}$ and $\mathrm{V}_{2} \mathrm{O}_{5}-\mathrm{CS}$, respectively. A redshifted emission is observed in the $\mathrm{V}_{2} \mathrm{O}_{5}-\mathrm{CS}$ nanohybrid due to the successfully incorporation of $\mathrm{V}_{2} \mathrm{O}_{5}$ nanoparticles into the electron-rich CS polymer chains. ${ }^{34}$

The FTIR spectra of CS, nanostructured $\mathrm{V}_{2} \mathrm{O}_{5}$, and the $\mathrm{V}_{2} \mathrm{O}_{5^{-}}$ CS nanohybrid film are shown in Fig. 3(A) in which the
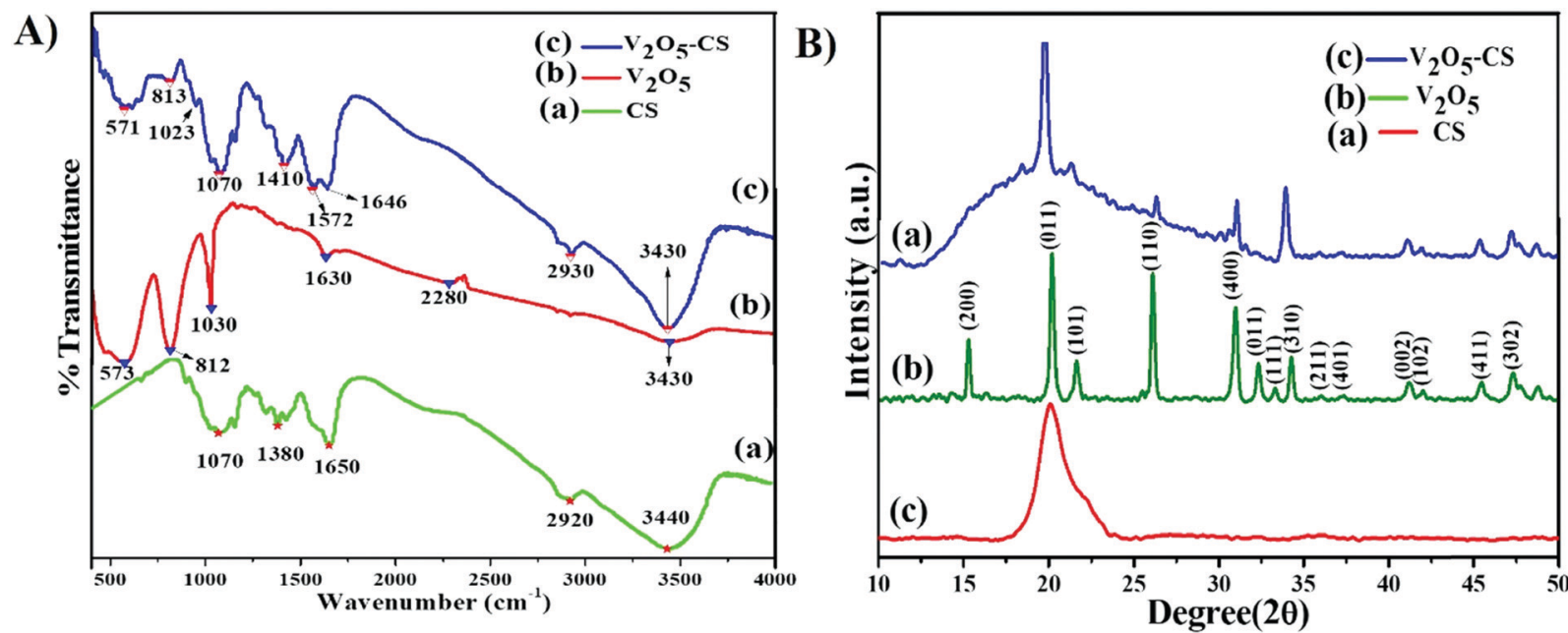

Fig. 3 (A) FT-IR transmission spectra: (a) $\mathrm{CS}$, (b) $\mathrm{V}_{2} \mathrm{O}_{5}$ nanoparticles and (c) $\mathrm{V}_{2} \mathrm{O}_{5}-\mathrm{CS}$ nanohybrid; and (B) $\mathrm{X}$-ray diffraction patterns: (a) $\mathrm{CS}$, (b) $\mathrm{V}_{2} \mathrm{O}_{5}$ nanoparticles and (c) $\mathrm{V}_{2} \mathrm{O}_{5}-\mathrm{CS}$ nanohybrid. 
vibrational spectrum of CS (green curve (a)) demonstrates a characteristic peak at $3440 \mathrm{~cm}^{-1}$ owing to overlap of $-\mathrm{NH}_{2}$ and -OH stretching bands, and the bands exhibited at $2920 \mathrm{~cm}^{-1}$ and $1650 \mathrm{~cm}^{-1}$ are the $\mathrm{CH}_{2}$ and carbonyl $(\mathrm{C}=\mathrm{O})$ stretching bands of amide I and amide II, respectively; the peak at $1380 \mathrm{~cm}^{-1}$ is the result of the $-\mathrm{C}-\mathrm{O}$ stretching mode of the $-\mathrm{CH}_{2}-\mathrm{OH}$ groups, and finally the peak at $1070 \mathrm{~cm}^{-1}$ is due to the stretching vibration of $\mathrm{C}-\mathrm{O}-\mathrm{C}$ in the glucose ring of $\mathrm{CS}^{38,39}$ Furthermore, the vibration spectrum of the $\mathrm{V}_{2} \mathrm{O}_{5}$ nanoparticles (Fig. 3(A) [red curve (b)]) yielded weak bands at $3430 \mathrm{~cm}^{-1}$ due to the different vibration modes of $\mathrm{O}-\mathrm{H}$ stretching due to physically adsorbed water. Moreover, the three broad peaks centered at 573,812 , and $1030 \mathrm{~cm}^{-1}$ are ascribed to the stretching vibration of $\mathrm{V}-\mathrm{O}$, the bending vibrations of $\mathrm{V}-\mathrm{O}-\mathrm{V}$, and the vibration of stretching between the shortest bonds of vanadium and oxygen, respectively. ${ }^{40}$ It is evident from Fig. 3(A) [blue curve (c)] that the vibrational spectrum obtained has similar vibration spectral bands that correspond to the functional group of CS, and the other bands at 571 and $813 \mathrm{~cm}^{-1}$ are the result of the stretching vibration of $\mathrm{V}-\mathrm{O}$ and the bending vibration of $\mathrm{V}-\mathrm{O}-\mathrm{V}$, respectively; thus, it can be concluded from this that the $\mathrm{V}_{2} \mathrm{O}_{5}-\mathrm{CS}$ nanohybrid was successfully synthesized.

The X-ray diffraction (XRD) analysis of $\mathrm{CS}, \mathrm{V}_{2} \mathrm{O}_{5}$, and $\mathrm{V}_{2} \mathrm{O}_{5^{-}}$ CS is presented in Fig. 3(B). Here, the red curve (c) demonstrates the XRD spectrum of pure CS, which exhibits a broad diffraction peak at a $2 \theta$ value of $20.3^{\circ}$, indicating the amorphous structure of CS; this broad peak thereby indicates the long-range disorder commonly found in polymer samples. ${ }^{37}$ Furthermore, the XRD peak patterns of the $\mathrm{V}_{2} \mathrm{O}_{5}$ nanoparticles [green curve (b)] and the $\mathrm{V}_{2} \mathrm{O}_{5}-\mathrm{CS}$ nanohybrid [blue curve (a)] are relative reflections of each other, as all the patterns show the reflection planes from (2 000$),\left(\begin{array}{lll}0 & 0 & 1\end{array}\right),\left(\begin{array}{lll}1 & 0 & 1\end{array}\right),\left(\begin{array}{lll}1 & 1 & 0\end{array}\right),\left(\begin{array}{lll}4 & 0 & 0\end{array}\right)$, ((0 11 1), (1 $\left.\begin{array}{lll}1 & 1 & 1\end{array}\right),\left(\begin{array}{lll}3 & 1 & 0\end{array}\right),\left(\begin{array}{lll}2 & 1 & 1\end{array}\right),\left(\begin{array}{lll}4 & 0 & 1\end{array}\right),\left(\begin{array}{lll}0 & 0 & 2\end{array}\right),\left(\begin{array}{lll}1 & 0 & 2\end{array}\right),\left(\begin{array}{lll}4 & 1 & 1\end{array}\right)$, and ( $\left.\begin{array}{lll}3 & 0 & 2\end{array}\right)$, which indicates that the $\mathrm{V}_{2} \mathrm{O}_{5}$ nanoparticles and $\mathrm{V}_{2} \mathrm{O}_{5}-$ CS nanohybrid have an orthogonal type of structure and all these corresponding peak points match with the reported values of the Joint Committee's database on Powder Diffraction Standards (JCPDS) card number 41-1426 ( $a=11.5160 \AA$, $b=3.5656 \AA$, and $c=4.3727 \AA) .{ }^{41}$ Apart from these peaks, no foreign phases (diffraction peaks of any impurities) were detected, confirming that the synthesized $\mathrm{V}_{2} \mathrm{O}_{5}$ samples were highly pure. Furthermore, in the $\mathrm{V}_{2} \mathrm{O}_{5}-\mathrm{CS}$ nanohybrid [blue curve (a)], a broad peak at $2 \theta$ at $\sim 21^{\circ}$ is observed, which may be linked to the CS phase due to intermolecular hydrogen bonds and the steric effects between the polymer chains and $\mathrm{V}_{2} \mathrm{O}_{5}$ nanoparticles. ${ }^{42}$ Furthermore, the average crystallite diameter (d) values calculated using Scherrer's equation [eqn (1)] are $\sim 25$ and $\sim 21 \mathrm{~nm}$ for the $\mathrm{V}_{2} \mathrm{O}_{5}$ nanoparticles and $\mathrm{V}_{2} \mathrm{O}_{5}-\mathrm{CS}$ nanohybrids, respectively, from the full width at half maximum (FWHM) of the most intense peak (lllll) of the XRD. In eqn (1),

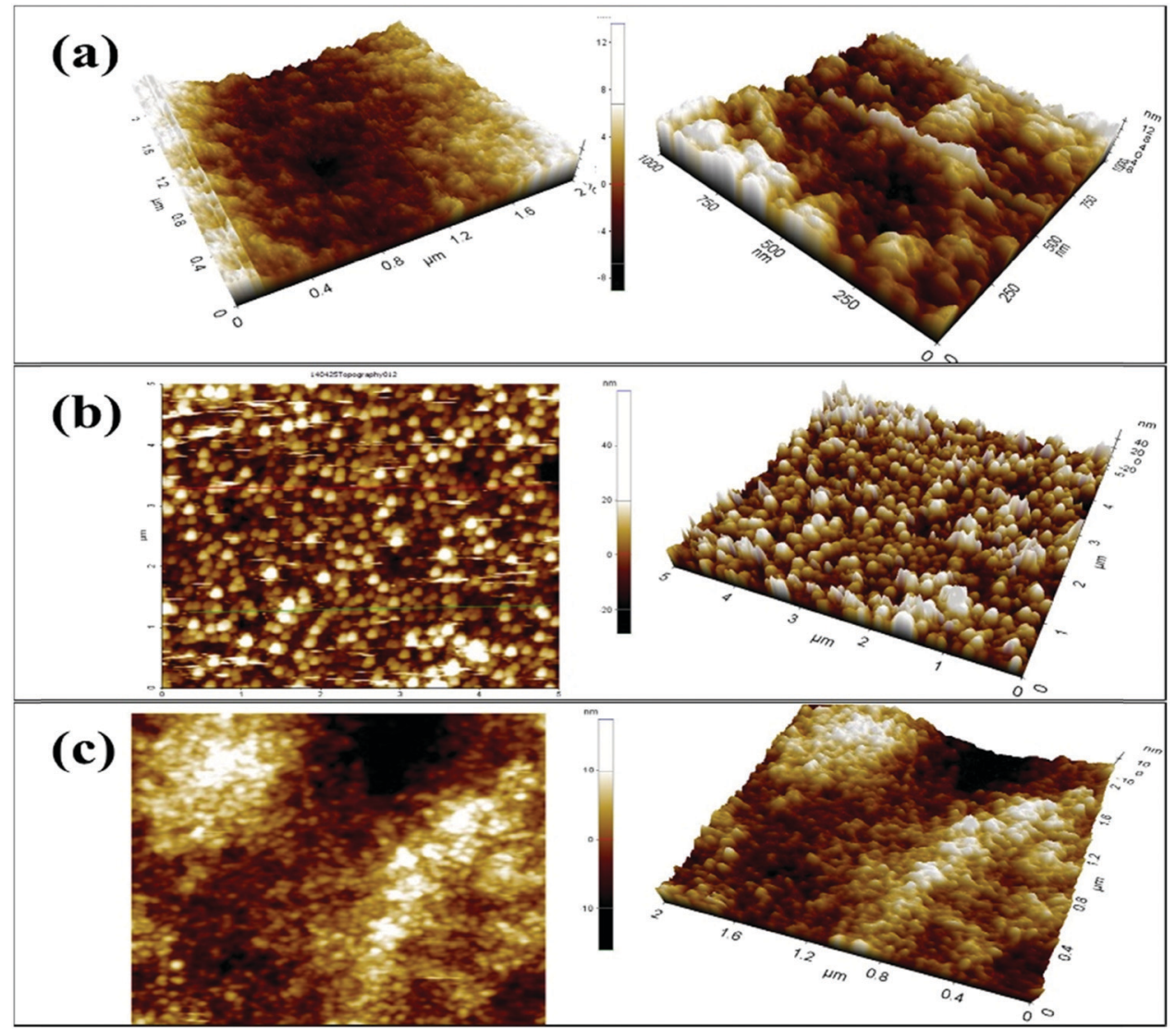

Fig. 4 Two- and three-dimensional AFM micrographs: (a) CS/ITO film, (b) $\mathrm{V}_{2} \mathrm{O}_{5} / \mathrm{ITO}$ film and (c) $\mathrm{V}_{2} \mathrm{O}_{5}-\mathrm{CS} / \mathrm{ITO}$ nanohybrid film. 
(a)

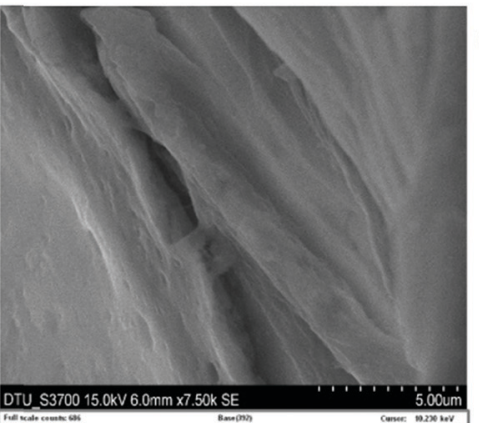

(d)

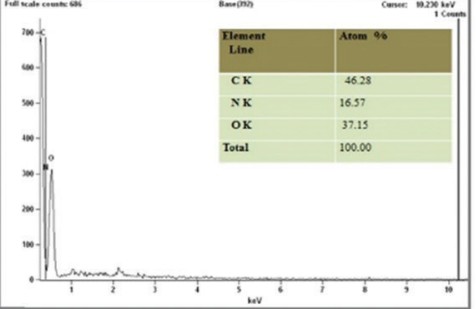

(b)

(e)
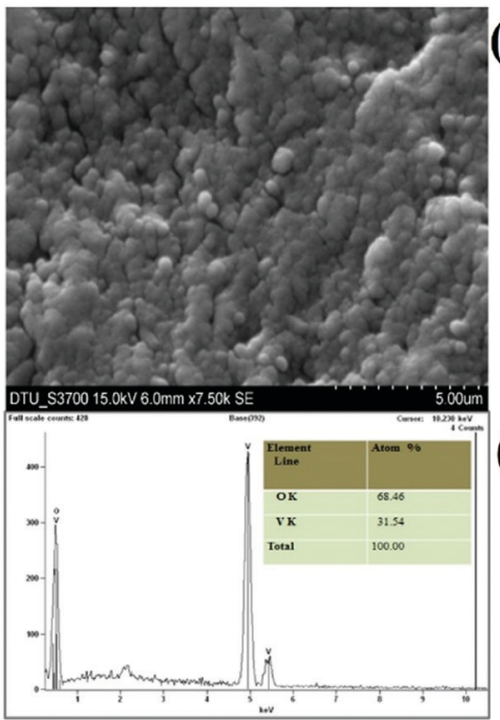

(c)

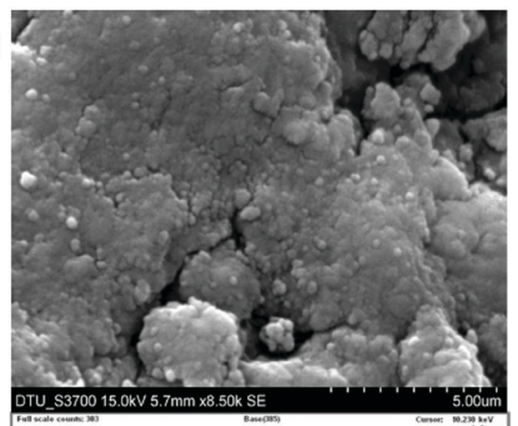

(f)

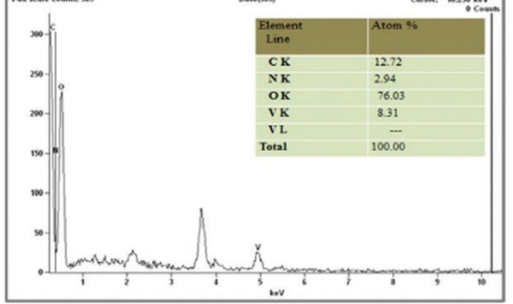

Fig. 5 SEM micrographs and EDX analysis: (a and d) CS film, (b and e) $V_{2} \mathrm{O}_{5}$ nanoparticles, and (c and f) $V_{2} \mathrm{O}_{5}-C S$ nanohybrid film.

$\beta$ is the FWHM value (radians), ' $\lambda$ ' is $1.5406 \AA$, which is the $\mathrm{CuK} \alpha$ wavelength, and $\theta$ is the Bragg diffraction.

$$
d=\frac{0.9 \lambda}{\beta \cos \theta}
$$

Moreover, atomic force microscopy (AFM) was utilized to study the surface properties of the $\mathrm{CS}, \mathrm{V}_{2} \mathrm{O}_{5}$ nanoparticles, and $\mathrm{V}_{2} \mathrm{O}_{5^{-}}$ CS nanohybrid film deposited on the ITO substrate to form the electrode, and the obtained morphological characteristics are demonstrated in Fig. 4. The three-dimensional morphology of the CS/ITO film surface demonstrates smooth, homogeneous, and bulbous structural elements [Fig. 4(a)]. Furthermore, in Fig. 4(b), the surface morphology of the $\mathrm{V}_{2} \mathrm{O}_{5}$ nanoparticles on the ITO is demonstrated, where the nanoparticles are uniformly distributed, and the roughness analysis revealed the root mean square roughness $\left(\mathrm{RMS}-R_{\mathrm{q}}\right)=6.0 \mathrm{~nm}$, the roughness average $\left(R_{\mathrm{a}}\right)=5.1 \mathrm{~nm}$, and the maximum peak height profile $=11.3 \mathrm{~nm}$. The 2D and 3D morphologies of the $\mathrm{V}_{2} \mathrm{O}_{5}-\mathrm{CS} / \mathrm{ITO}$ nanohybrid film [Fig. 4(c)] demonstrate how the nanoparticles are incorporated into the CS layer with RMS- $R_{\mathrm{q}}, R_{\mathrm{a}}$, and maximum peak height profiles of $3.2 \mathrm{~nm}, 2.5 \mathrm{~nm}$, and $9.3 \mathrm{~nm}$, respectively. Thus, these results show that the roughness is decreased compared with the $\mathrm{V}_{2} \mathrm{O}_{5} / \mathrm{ITO}$ nanoparticle surface due to the presence of CS; from this, it can be said that the obtained $\mathrm{V}_{2} \mathrm{O}_{5^{-}}$ CS film on the ITO surface is a smooth nanohybrid film with incorporated $\mathrm{V}_{2} \mathrm{O}_{5}$ nanoparticles as $\mathrm{CS}$ is a biopolymer. Furthermore, SEM analysis was also carried out to investigate the surface morphologies of CS, the $\mathrm{V}_{2} \mathrm{O}_{5}$ nanoparticles, and the $\mathrm{V}_{2} \mathrm{O}_{5}-\mathrm{CS}$ nanohybrid film deposited on the ITO substrate to form the electrode. Porous, thick, and uniform layers of CS are visible in Fig. 5(a). From the SEM micrograph of the $\mathrm{V}_{2} \mathrm{O}_{5}$ nanoparticles [Fig. 5(b)], it can be seen that the nanoparticles are uniformly dispersed on the ITO surface, and apart from this it can also be observed that they are densely distributed owing to deposition via the EPD process. Fig. 5(c) reveals the globular morphology of the formed nanohybrid film, indicating the successful synthesis of the $\mathrm{V}_{2} \mathrm{O}_{5}-\mathrm{CS}$ nanohybrid, formed due to electrostatic interactions between the cationic CS and the

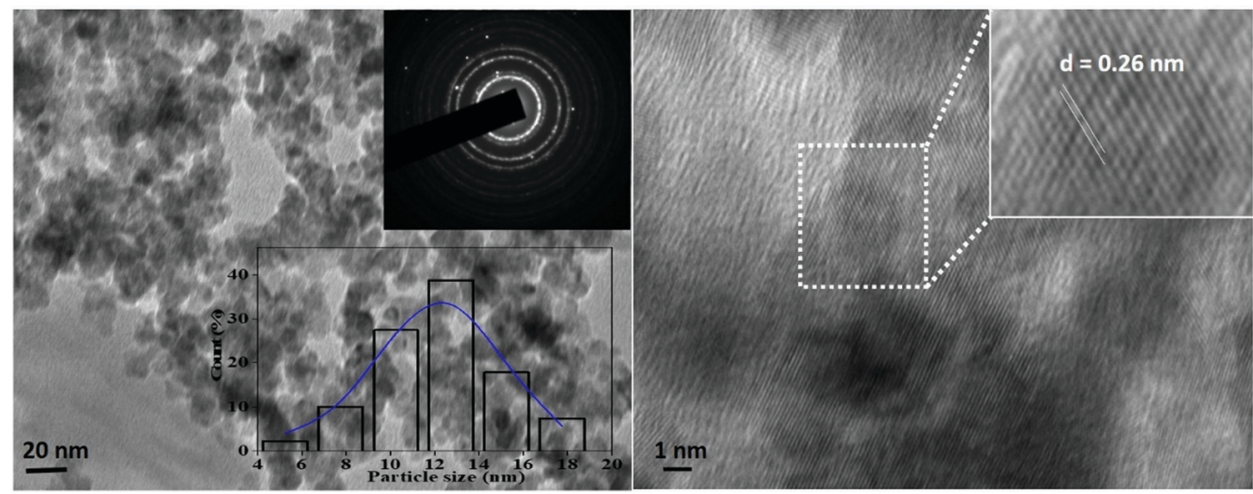

Fig. 6 TEM and HR-TEM images with inset images showing the corresponding SAED image and the size distribution histogram fitted by Lorentzian function of $\mathrm{V}_{2} \mathrm{O}_{5}$ nanoparticles prepared via the hydrothermal method. 

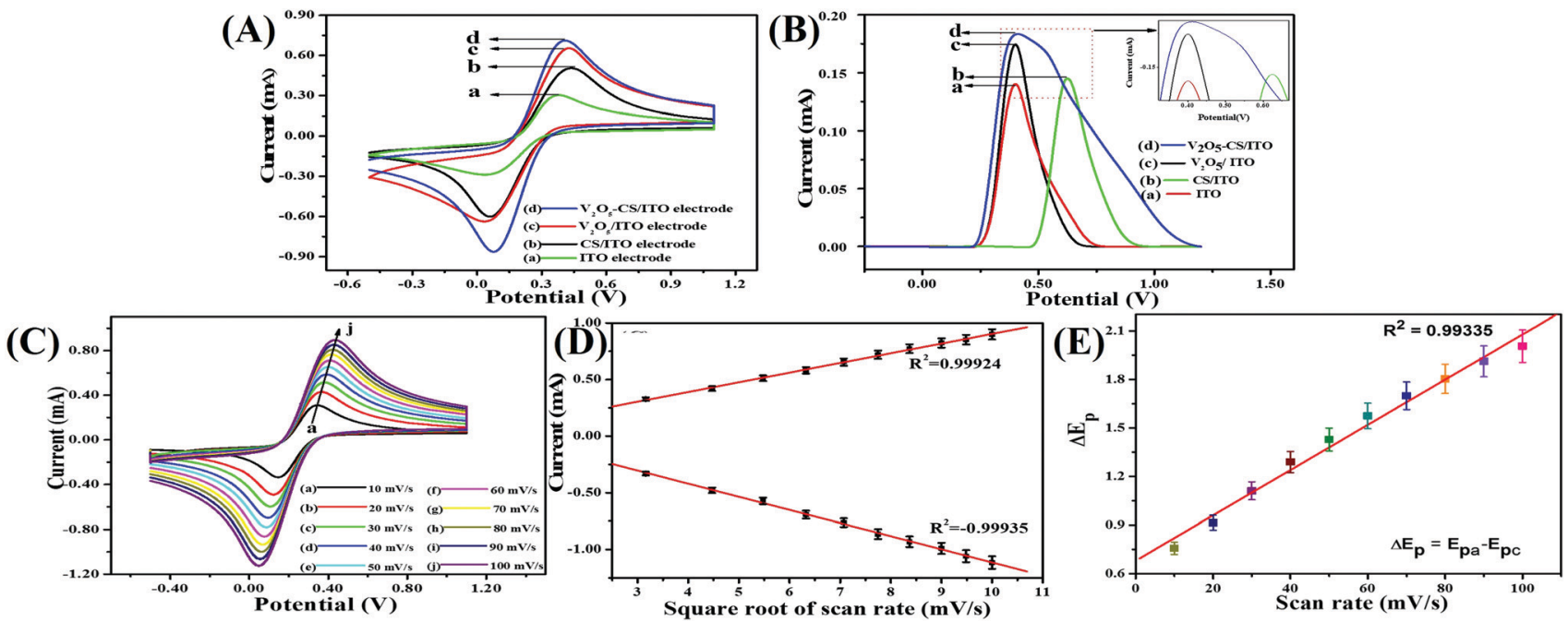

Fig. 7 (A) Cyclic voltammograms of the (a) ITO, (b) CS/ITO, (c) $\mathrm{V}_{2} \mathrm{O}_{5}-\mathrm{CS} / \mathrm{ITO}$, and (d) $\mathrm{V}_{2} \mathrm{O}_{5}-\mathrm{CS} / \mathrm{ITO}$ electrodes; (B) DPV results of the (a) ITO, (b) CS/ITO, (c) $\mathrm{V}_{2} \mathrm{O}_{5}-\mathrm{CS} / \mathrm{ITO}$, and (d) $\mathrm{V}_{2} \mathrm{O}_{5}-\mathrm{CS} / \mathrm{ITO}$ electrodes; (C) scan-rate studies from 10 to $100 \mathrm{mV} \mathrm{s}^{-1}$ for the $\mathrm{V}_{2} \mathrm{O}_{5}-\mathrm{CS} / \mathrm{ITO}$ electrode; (D) the magnitude of current vs. potential difference as a function of the square root of the scan rate $\left(10-100 \mathrm{mV} \mathrm{s}^{-1}\right)$; and $(E)$ the magnitude of the potential difference $\left(\Delta E_{\mathrm{p}}\right)$ as a function of the scan rate $\left(10-100 \mathrm{mV} \mathrm{s}^{-1}\right)$.

presence of surface charges on the $\mathrm{V}_{2} \mathrm{O}_{5}$ nanoparticles, which help in the grafting of the $\mathrm{V}_{2} \mathrm{O}_{5}$ nanoparticles into the CS polymer network. Fig. 5(d)-(f) show the EDX spectra of CS/ ITO, $\mathrm{V}_{2} \mathrm{O}_{5} / \mathrm{ITO}$ and $\mathrm{V}_{2} \mathrm{O}_{5}-\mathrm{CS} / \mathrm{ITO}$ film, respectively. The atomic percentage of $\mathrm{C}, \mathrm{N}$ and $\mathrm{O}$ for the CS/ITO electrodes are 46.28, 16.57 and $37.15 \%$, respectively, while in the $\mathrm{V}_{2} \mathrm{O}_{5} / \mathrm{ITO}$ film the atomic percentages of $\mathrm{V}$ and $\mathrm{O}$ are 68.46 and $31.54 \%$, respectively, with the absence of other elements indicating the high purity of the synthesized nanoparticles. The EDX data of the $\mathrm{V}_{2} \mathrm{O}_{5}-\mathrm{CS} / \mathrm{ITO}$ nanohybrid film show atomic\% values for $\mathrm{C}$ $(12.72 \%)$ and $\mathrm{N}(2.94 \%)$, indicating the presence of CS molecules, and confirming the formation of the nanohybrid. In addition to these studies, TEM analysis of the $\mathrm{V}_{2} \mathrm{O}_{5}$ nanoparticles was also carried out and is presented in Fig. 6 . The TEM image reveals that the $\mathrm{V}_{2} \mathrm{O}_{5}$ nanoparticles retained a homogeneous spherical morphology, and these particles range from 10 to $35 \mathrm{~nm}$ in size. The average particle size of the $\mathrm{V}_{2} \mathrm{O}_{5}$ nanoparticles was around $\sim 12 \mathrm{~nm}$, which was obtained by a histogram fitted by the Lorentzian function. Furthermore, the interplanar spacing ' $d=0.26 \mathrm{~nm}$ ' is consistent with the prominent $\left(\begin{array}{lll}0 & 1 & 1\end{array}\right)$ diffraction peak observed in the XRD study; in addition to this, the selected area electron diffraction image (top-right inset in Fig. 6) is similar to the JCPDS card data values of $d$-spacing, which corresponds to the highly intense peak of the XRD study.

\subsection{Electrochemical studies}

3.2.1. Cyclic voltammetry (CV) and differential pulse voltammetry (DPV). The redox electrochemical behavior of the plain ITO, CS/ITO, and $\mathrm{V}_{2} \mathrm{O}_{5} / \mathrm{ITO}$, and $\mathrm{V}_{2} \mathrm{O}_{5}$-CS/ITO electrodes were studied in $50 \mathrm{mM}$ PBS solution $(0.9 \% \mathrm{NaCl})$ of $\mathrm{pH} 6.4$ containing $\left[\mathrm{Fe}(\mathrm{CN})_{6}\right]^{3-14-}$ of $5 \mathrm{mM}$ at a scan rate of $50 \mathrm{mV} \mathrm{s}^{-1}$ [Fig. 7(A)]. The green curve in Fig. 7(A) is the cyclic voltammogram of the plain ITO electrode, which exhibits oxidation and reduction peaks due to the presence of the $\left[\mathrm{Fe}(\mathrm{CN})_{6}\right]^{3-/ 4-}$ mediator, which demonstrates the anodic/oxidation current peak $\left(I_{\mathrm{pa}}\right)$ at $0.303 \mathrm{~mA}$. Furthermore, the black, red, and blue curves in Fig. 7(A) are of the CS/ITO, $\mathrm{V}_{2} \mathrm{O}_{5} / \mathrm{ITO}$, and $\mathrm{V}_{2} \mathrm{O}_{5}-\mathrm{CS} /$ ITO electrodes, respectively, and demonstrate the anodic/oxidation current peak $\left(I_{\mathrm{pa}}\right)$ values of $0.506,0.658$, and $0.714 \mathrm{~mA}$, respectively. The current increase that is observed in the CS/ITO electrode compared with the plain ITO electrode is due to the cationic nature of the CS, which helps to accept electrons. ${ }^{43}$ The $I_{\mathrm{pa}}$ value of the $\mathrm{V}_{2} \mathrm{O}_{5} / \mathrm{ITO}$ electrode is more than those of the plain ITO and CS/ITO electrodes, confirming that the metal oxide $\mathrm{V}_{2} \mathrm{O}_{5}$ is an excellent conducting material with a large surface area. Further, the $I_{\mathrm{pa}}$ value of the $\mathrm{V}_{2} \mathrm{O}_{5}-\mathrm{CS} / \mathrm{ITO}$ electrode is the highest among the other fabricated electrodes, and this is as a result of the $\mathrm{V}_{2} \mathrm{O}_{5}$ nanoparticles being incorporated into the biopolymer CS matrix, which increases the electroactive surface area obtained from the high electrocatalytic mobility, resulting in improvement of the electron transfer. Furthermore, the DPV results were in complete agreement with the CV behavior of the ITO, CS/ITO, $\mathrm{V}_{2} \mathrm{O}_{5} / \mathrm{ITO}$, and $\mathrm{V}_{2} \mathrm{O}_{5}-\mathrm{CS} / \mathrm{ITO}$ electrodes, and it also suggested that the $\mathrm{V}_{2} \mathrm{O}_{5}$ nanoparticles incorporated into the CS biopolymer provide greater electron transport and an enhanced electrocatalytic behavior between the mediator and the electrode [Fig. 7(B)].

3.2.2. Scan-rate effect. For studying the interfacial kinetics of the $\mathrm{V}_{2} \mathrm{O}_{5}-\mathrm{CS} / \mathrm{ITO}$ electrode, CV studies were performed by varying the scan rate from 10 to $100 \mathrm{mV} \mathrm{s}^{-1}$ [Fig. 7(C)] in a $50 \mathrm{mM}$ PBS solution $(0.9 \% \mathrm{NaCl})$ of $\mathrm{pH} 6.4$ containing $\left[\mathrm{Fe}(\mathrm{CN})_{6}\right]^{3-/ 4-}$ of $5 \mathrm{mM}$. From this study, it was evident that the magnitudes of the oxidation/anodic $\left(I_{\mathrm{pa}}\right)$ and reduction/ cathodic $\left(I_{\mathrm{pc}}\right)$ peak currents increase linearly when the current values are plotted against the square root of the scan rate $\left(\nu^{1 / 2}\right)$ [Fig. 7(D)]. Moreover, when the scan rate is varied from 10 to $100 \mathrm{mV} \mathrm{s}^{-1}$, with this increase in scan rate, the 


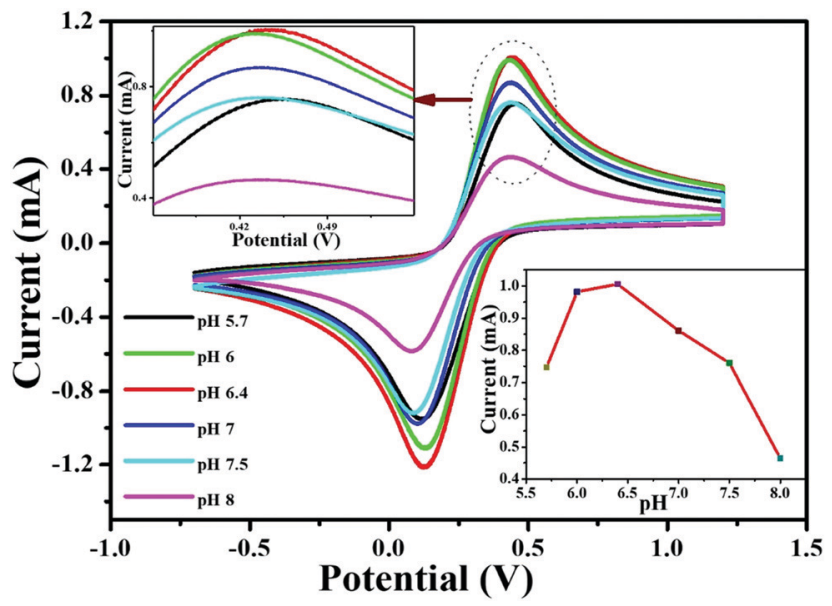

Fig. $8 \mathrm{CV}$ studies of the $\mathrm{V}_{2} \mathrm{O}_{5}-\mathrm{CS} / \mathrm{ITO}$ electrode as a function of $\mathrm{pH}$ ranging from 5.7 to 8.0 in phosphate buffer containing $\left[\mathrm{Fe}(\mathrm{CN})_{6}\right]^{3-/ 4-}$. Inset shows the current response of the $\mathrm{V}_{2} \mathrm{O}_{5}-\mathrm{CS} / \mathrm{ITO}$ electrode as a function of $\mathrm{pH}$.

oxidation/anodic and reduction/cathodic peaks start to shift towards a more positive potential and a more negative potential, respectively, which in turn suggests this redox (oxidation-reduction) behavior as a quasi-reversible process; furthermore, the potential peak shift $\left(\Delta E_{\mathrm{p}}=E_{\mathrm{pa}}-E_{\mathrm{pc}}\right)$ also exhibits a linear association [Fig. 7(E)] with the scan rate, suggesting this process at the electrode of electrochemical reaction as a diffusion-controlled process, and the obtained linear fit $\left(R^{2}=0.99335\right)$ of the peak height against the scan rate suggests enhanced electrocatalytic behavior.

3.2.3. Kinetic studies. The electron-transfer coefficient $\left(K_{\mathrm{S}}\right)$ of ITO modified by $\mathrm{V}_{2} \mathrm{O}_{5}-\mathrm{CS}$ is calculated using eqn $(2)^{12}$ in which ' $F$ ' is the Faraday constant $\left(96485 \mathrm{C} \mathrm{mol}^{-1}\right)$, the gas constant is denoted by ' $R$ ' $\left(8.314 \mathrm{~J} \mathrm{~mol}^{-1} \mathrm{~K}^{-1}\right)$, the peak-to-peak separation (in $\mathrm{V}$ ) is denoted by $m$, the number of electrons is denoted by $n, \nu$ is the scan rate, and $T$ is the temperature (which in this case is a room temperature of $300 \mathrm{~K}$ ). Thus, by putting these values into eqn (2), $K_{\mathrm{S}}$ was obtained for $\mathrm{V}_{2} \mathrm{O}_{5}-\mathrm{CS} / \mathrm{ITO}$ electrode as $0.601142 \mathrm{~s}^{-1}$; this value indicates an increased rate of electron transfer, which is a result of the higher catalytic behavior of the $\mathrm{V}_{2} \mathrm{O}_{5}$ nanoparticles. Furthermore, the Brown-Anson model [eqn (3)] ${ }^{12}$ was used to determine the $\mathrm{V}_{2} \mathrm{O}_{5}-\mathrm{CS} / \mathrm{ITO}$ electrode's surface concentration $(Y)$; here, $A$ denotes the surface area of the electrode $\left(0.25 \mathrm{~cm}^{2}\right), I_{\mathrm{p}}$ is the peak current of the electrode $\left(I_{\mathrm{pc}}\right.$ and $\left.I_{\mathrm{pa}}\right)$, and the remaining other values are as stated above. Thus, putting these values in eqn (3), the obtained $Y$ value was $3.67 \times 10^{-6} \mathrm{~mol} \mathrm{~cm}^{-2}$, suggesting an increased electroactive surface area. Moreover, for calculating the diffusion coefficient $(D)$ for $5 \mathrm{mM}$ $\left[\mathrm{Fe}(\mathrm{CN})_{6}\right]^{3-/ 4-}$ diffusion from the electrolyte to the surface of $\mathrm{V}_{2} \mathrm{O}_{5}-\mathrm{CS} / \mathrm{ITO}$ electrode, the Randles-Ševčik equation [eqn (4)] $]^{12}$ was employed in which $C$ denotes the mediator concentration at the surface (in this case, it is $0.000005 \mathrm{~mol} \mathrm{~cm}^{-3}$ ), and the other values are as stated for eqn (2) and (3). Putting the values into eqn (4), the obtained $D$ value is $1.27368 \mathrm{~cm}^{2} \mathrm{~s}^{-1}$.

$$
\begin{gathered}
K_{\mathrm{S}}=m n F \nu / R T \\
I_{\mathrm{p}}=n^{2} F^{2} Y A V / 4 R T \\
I_{\mathrm{p}}=\left(2.69 \times 10^{5}\right) n^{3 / 2} A D^{1 / 2} C \nu^{1 / 2}
\end{gathered}
$$

3.2.4. pH optimization. Before starting the experiments, initially, the $\mathrm{pH}$ of the final electrode $\left(\mathrm{V}_{2} \mathrm{O}_{5}-\mathrm{CS} / \mathrm{ITO}\right)$ was optimized via CV analysis in a $50 \mathrm{mM}$ PBS solution $(0.9 \% \mathrm{NaCl})$ containing $5 \mathrm{mM}\left[\mathrm{Fe}(\mathrm{CN})_{6}\right]^{3-/ 4-}$ of varying $\mathrm{pH}(5.7$ to 8$)$ at a scan rate of $50 \mathrm{mV} \mathrm{s}^{-1}$ (Fig. 8). This study observed that the $I_{\mathrm{pa}}$ value increases from pH 5.7 to 6.4 and then starts to deteriorate as the $\mathrm{pH}$ is increased further. Moreover, it was observed that at $\mathrm{pH}$ 6.4, the $\mathrm{V}_{2} \mathrm{O}_{5}-\mathrm{CS} / \mathrm{ITO}$ electrode demonstrated the highest current magnitude (inset of Fig. 8) owing to the enhanced rate of interaction between the electrode and the mediator $\left[\mathrm{Fe}(\mathrm{CN})_{6}\right]^{3-/ 4-}$ compared with the other $\mathrm{pH}$ conditions. The lower $I_{\mathrm{pa}}$ values for the other $\mathrm{pH}$ conditions is due to the limited electron transport between the $\mathrm{V}_{2} \mathrm{O}_{5}-\mathrm{CS} / \mathrm{ITO}$ electrode and the medium. Thus, for this study's overall $\mathrm{CV}$ analysis, $\mathrm{pH} 6.4$ was selected as the optimum $\mathrm{pH}$ condition.

3.2.5. Electro-oxidation study of hydrazine. Regarding human toxicity issues caused by hydrazine, in this study the electrochemical sensing response of the $\mathrm{V}_{2} \mathrm{O}_{5}-\mathrm{CS} / \mathrm{ITO}$ nanohybrid electrode to hydrazine was demonstrated via the fabrication of a
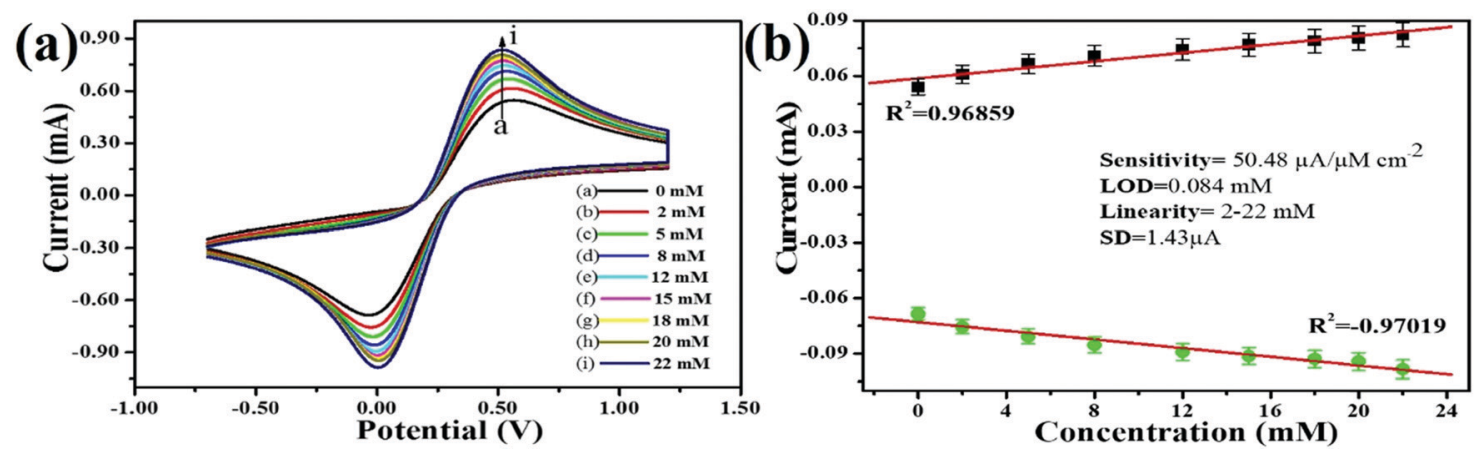

Fig. 9 (A) Electro-oxidation response study of the $\mathrm{V}_{2} \mathrm{O}_{5}-\mathrm{CS} / \mathrm{ITO}$ electrode with respect to the hydrazine concentration (2-22 $\mathrm{mM}$ ) in PBS (5 mM, $\mathrm{pH} 6.4,0.9 \% \mathrm{NaCl}$ ) containing $\left[\mathrm{Fe}(\mathrm{CN})_{6}\right]^{3-/ 4-}$ at a scan rate of $50 \mathrm{mV} \mathrm{s}^{-1}$. (B) Calibration curve of the $\mathrm{V}_{2} \mathrm{O}_{5}-\mathrm{CS} / \mathrm{ITO}$ electrode and the variation in current as a function of the hydrazine concentration $(2-22 \mathrm{mM})$ in PBS $(5 \mathrm{mM}, 6.4 \mathrm{pH}, 0.9 \% \mathrm{NaCl})$ containing $\left[\mathrm{Fe}(\mathrm{CN})_{6}\right]^{3-/ 4-}$ at a scan rate of $50 \mathrm{mV} \mathrm{s}{ }^{-1}$. 
Table 1 Sensing parameters for hydrazine utilizing different electrode materials

\begin{tabular}{|c|c|c|c|c|c|c|c|}
\hline Method & Electrode material & $\begin{array}{l}\mathrm{pH}, \\
\text { medium }\end{array}$ & Sensitivity & Linear range & LOD & $\begin{array}{l}\text { Response } \\
\text { time (s) }\end{array}$ & Ref. \\
\hline $\mathrm{CV}$ & $\begin{array}{l}\text { Pd-GG- } g \text {-PAM-silica } \\
\text { modified GCE }\end{array}$ & 7.0, PBS & - & $\begin{array}{l}0.05-0.6 \text { and } 0.6-180 \mathrm{mmol} \\
\mathrm{dm}^{-3}\end{array}$ & $\begin{array}{l}4.1 \times 10^{-3} \mathrm{mmol} \\
\mathrm{dm}^{-3}\end{array}$ & - & 39 \\
\hline $\mathrm{CV}$ & Pd NPs-modified CB & 9.0, PBS & - & $\begin{array}{l}0.005-0.5,0.5-10, \text { and } \\
10-50 \mathrm{mmol} \mathrm{dm}^{-3}\end{array}$ & $\begin{array}{l}8.8 \times 10^{-3} \mathrm{mmol} \\
\mathrm{dm}^{-3}\end{array}$ & - & 41 \\
\hline Amperometry & $\mathrm{Au} @ P d / \mathrm{rGO} / \mathrm{GCE}$ & 6.8, PBS & $0.825 \mathrm{~A} \mathrm{~L} \mathrm{~mol}^{-1}$ & $2.0-40 \mu \mathrm{M}$ liter $^{-1}$ & $0.08 \mu \mathrm{M}$ liter $^{-1}$ & - & 42 \\
\hline Amperometry & $\begin{array}{l}\mathrm{Fe}_{2} \mathrm{O}_{3} \text {-modified carbon } \\
\text { powder epoxy composite } \\
\text { electrode }\end{array}$ & 7.4, PBS & - & - & $\begin{array}{l}1.18 \times 10^{-3} \mathrm{mmol} \\
\mathrm{dm}^{-3}\end{array}$ & $\sim 60$ & 44 \\
\hline $\mathrm{CV}$ & $\mathrm{m}-\mathrm{Fe}_{3} \mathrm{O}_{4} / \mathrm{GO} / \mathrm{GCE}$ & 7.1, PBS & - & $1.0-4400 \mu \mathrm{M}$ & $0.059 \mu \mathrm{M}$ & - & 45 \\
\hline Amperometry & Au@Pd/CB-DHP/GCE & 10, PBS & $0.0824 \mathrm{~A} \mathrm{~L} \mathrm{~mol}^{-1}$ & $2.5-88 \mu \mathrm{M}$ liter $^{-1}$ & $1.77 \mu \mathrm{M}$ liter $^{-1}$ & - & 46 \\
\hline Amperometry & $\mathrm{CuO} / \mathrm{CNTs}-\mathrm{rGO} / \mathrm{GCE}$ & - & 4.28 & $1.2-430 \mu \mathrm{M}$ & $0.20 \mu \mathrm{M}$ & - & 47 \\
\hline Amperometry & $\mathrm{V}_{2} \mathrm{O}_{5}-\mathrm{CS} / \mathrm{ITO}$ & 6.4, PBS & $\begin{array}{l}50.48 \\
\mathrm{~cm}^{-2}\end{array}$ & $2-22 \mathrm{mM}$ & $0.084 \mathrm{mM}$ & 20 & $\begin{array}{l}\text { Present } \\
\text { work }\end{array}$ \\
\hline
\end{tabular}

fast, selective, and efficient $\mathrm{V}_{2} \mathrm{O}_{5}-\mathrm{CS} /$ ITO nanohybrid-based electrochemical sensing device for detection of hydrazine to help avoid human exposure. For the measurement of different hydrazine concentrations, CV analysis was performed in which the $\mathrm{V}_{2} \mathrm{O}_{5}-\mathrm{CS} /$
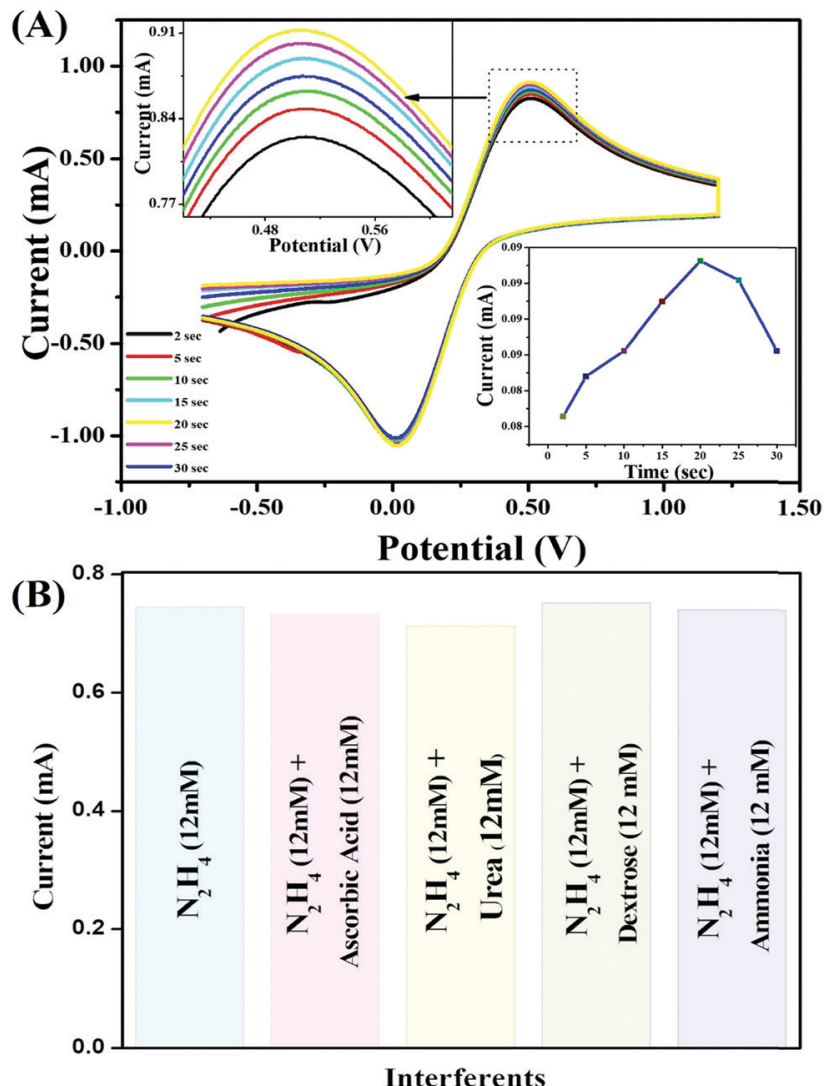

Fig. 10 (A) $\mathrm{CV}$ study of the electrochemical response times of the $\mathrm{V}_{2} \mathrm{O}_{5}-$ CS/ITO nanohybrid electrode; inset image shows the current response versus the incubation time for the $\mathrm{V}_{2} \mathrm{O}_{5}-\mathrm{CS} / \mathrm{ITO}$ nanohybrid electrode. (B) Interference study of the $\mathrm{V}_{2} \mathrm{O}_{5}-\mathrm{CS} / \mathrm{ITO}$ electrode with ascorbic acid $(12 \mathrm{mM})$, urea $(12 \mathrm{mM})$, dextrose $(12 \mathrm{mM})$, and ammonia $(12 \mathrm{mM})$ as interferent materials.
ITO nanohybrid electrode was exposed to various concentrations of hydrazine $\left(\mathrm{N}_{2} \mathrm{H}_{4} ; 2-22 \mathrm{mM}\right)$ in a $50 \mathrm{mM}$ PBS solution $(0.9 \% \mathrm{NaCl})$ of $\mathrm{pH} 6.4$ containing $\left[\mathrm{Fe}(\mathrm{CN})_{6}\right]^{3-/ 4-}$ of $5 \mathrm{mM}$ at a scan rate of $50 \mathrm{mV} \mathrm{s}^{-1}$ [Fig. 9(A)]. From the CV study, it was observed that the oxidation/anodic peak current $\left(I_{\mathrm{pa}}\right)$ increases linearly with the increasing concentration of $\mathrm{N}_{2} \mathrm{H}_{4}$, and the reduction/cathodic peak current $\left(I_{\mathrm{pc}}\right)$ decreases linearly with the increasing concentration of $\mathrm{N}_{2} \mathrm{H}_{4}$, suggesting that the $\mathrm{V}_{2} \mathrm{O}_{5}-\mathrm{CS} / \mathrm{ITO}$ nanohybrid electrode is sensitive towards $\mathrm{N}_{2} \mathrm{H}_{4}$. The chemical overview of the electrochemical reduction of $\mathrm{N}_{2} \mathrm{H}_{4}$ by the $\mathrm{V}_{2} \mathrm{O}_{5}-\mathrm{CS} / \mathrm{ITO}$ nanohybrid electrode in the presence of the mediator $\left[\mathrm{Fe}(\mathrm{CN})_{6}\right]^{3-/ 4-}$ is demonstrated in eqn (5) below.

$$
\mathrm{N}_{2} \mathrm{H}_{4}+4 \mathrm{OH}^{-} \stackrel{\left[\mathrm{Fe}(\mathrm{CN})_{6}\right]^{3^{-} / 4^{-}}}{\longrightarrow} \mathrm{N}_{2}+4 \mathrm{H}_{2} \mathrm{O}+4 \mathrm{e}^{-}
$$

As it was observed that the oxidation/anodic current $\left(I_{\mathrm{pa}}\right)$ and reduction/cathodic current $\left(I_{\mathrm{pc}}\right)$ peaks had a linear relationship with various $\mathrm{N}_{2} \mathrm{H}_{4}$ concentrations from 2 to $22 \mathrm{mM}$ [Fig. 9(B)], and the obtained linear coefficient value $\left(R^{2}\right)$ was 0.96859 , which suggested a strong relationship between currents at oxidation $\left(I_{\mathrm{pa}}\right)$ /reduction $\left(I_{\mathrm{pc}}\right)$ peaks and the $\mathrm{N}_{2} \mathrm{H}_{4}$ concentrations. Further, from the obtained results, the limit of detection (LOD) was calculated using the standard formula $(3 \times \mathrm{SD} /$ sensitivity $)$ in which SD is the value of the standard deviation of the calibration plot slope and the background current; for determining the LOD, first sensitivity was calculated, and the obtained sensitivity was $50.48 \mu \mathrm{A} \mu \mathrm{M}^{-1} \mathrm{~cm}^{2}$, which suggested that the fabricated electrode was highly sensitive towards $\mathrm{N}_{2} \mathrm{H}_{4}$; then from further calculations, the obtained LOD was $0.084 \mathrm{mM}$. Thus, the electro-oxidation activity of the $\mathrm{V}_{2} \mathrm{O}_{5}-\mathrm{CS} / \mathrm{ITO}$ nanohybrid electrode at various concentrations of $\mathrm{N}_{2} \mathrm{H}_{4}$ suggests that the $\mathrm{V}_{2} \mathrm{O}_{5}-$ CS nanohybrid material used to fabricate the electrode is a promising material for the electrochemical sensing of $\mathrm{N}_{2} \mathrm{H}_{4}$ in the given sample, and the $\mathrm{V}_{2} \mathrm{O}_{5}-\mathrm{CS}$ nanohybrid is further put forward as a prominent material for fabricating a potential electrochemical device. Moreover, Table 1 compares this fabricated electrode with other pre-existing electrode materials used 
to determine $\mathrm{N}_{2} \mathrm{H}_{4},{ }^{44-52}$ which suggests that the electrode fabricated in this work has a better sensitivity.

3.2.6. Response time, reproducibility and selectivity/interference study of the $\mathrm{V}_{2} \mathrm{O}_{5}-\mathrm{CS} / \mathrm{ITO}$ electrode. The reproducibility of the $\mathrm{V}_{2} \mathrm{O}_{5}$-CS/ITO nanohybrid electrode was delineated utilizing the $\mathrm{CV}$ technique in a $50 \mathrm{mM}$ PBS solution $(0.9 \% \mathrm{NaCl})$ of $\mathrm{pH} 6.4$ containing $\left[\mathrm{Fe}(\mathrm{CN})_{6}\right]^{3-/ 4-}$ of $5 \mathrm{mM}$ at an optimized scan rate of $50 \mathrm{mV} \mathrm{s}^{-1}$ in the presence of $\mathrm{N}_{2} \mathrm{H}_{4}(8 \mathrm{mM})$. The results obtained from 15 repeated measurements using the same electrode (data not shown) indicated that the as-prepared $\mathrm{V}_{2} \mathrm{O}_{5}-\mathrm{CS} / \mathrm{ITO}$ electrode showed good reproducibility after 15 repeated measurements with good precision of about $2.3 \%$ at low SD. Furthermore, by utilizing similar reaction conditions, the response time was determined [Fig. 10(A)], for the $\mathrm{V}_{2} \mathrm{O}_{5}-\mathrm{CS} / \mathrm{ITO}$ nanohybrid electrode by measuring the electrochemical current responses between 2 and $30 \mathrm{~s}$. The magnitude of the current increases initially (2-20 s), and after $20 \mathrm{~s}$ the current started to deteriorate, indicating that $20 \mathrm{~s}$ is the optimum response time for the $\mathrm{V}_{2} \mathrm{O}_{5}-\mathrm{CS} / \mathrm{ITO}$ nanohybrid electrode for sensing $\mathrm{N}_{2} \mathrm{H}_{4}$ in the sample. Moreover, interference studies presented in Fig. 10(B) were also performed in the presence of ascorbic acid (12 $\mathrm{mM})$, urea $(12 \mathrm{mM})$, dextrose $(12 \mathrm{mM})$, and ammonia (12 mM), which demonstrated that no significant current change was observed.

\section{Conclusions}

In conclusion, we herein presented a method for the synthesis of $\mathrm{V}_{2} \mathrm{O}_{5}$ nanoparticles using a hydrothermal method followed by a melt-quenching method; these nanoparticles were further stabilized by functionalizing them with CS for fabricating a thin film electrode $\left(\mathrm{V}_{2} \mathrm{O}_{5}-\mathrm{CS} / \mathrm{ITO}\right)$ via casting an aqueous suspension of the $\mathrm{V}_{2} \mathrm{O}_{5}-\mathrm{CS}$ nanohybrid onto an indium-tin-oxide (ITO)coated glass electrode, to investigate the electrocatalytic activity of the nanohybrid towards hydrazine oxidation via cyclic voltammetry. The electrochemical response of the $\mathrm{V}_{2} \mathrm{O}_{5}-\mathrm{CS} / \mathrm{ITO}$ electrode showed a high sensitivity $\left(50.48 \mu \mathrm{A} \mu \mathrm{M}^{-1} \mathrm{~cm}^{-2}\right)$ for the electrochemical determination of hydrazine $(2-22 \mathrm{mM})$; the obtained LOD in this study was $0.084 \mathrm{mM}$ at a scan rate of $50 \mathrm{mV} \mathrm{s}^{-1}$, and the determined amperometric response time was $20 \mathrm{~s}$. Thus, the findings of this study suggest that the synthesized $\mathrm{V}_{2} \mathrm{O}_{5}-\mathrm{CS}$ nanohybrid material is a very promising agent for fabricating an electrochemical sensing platform for the label-free, rapid, and simple quantitative determination of $\mathrm{N}_{2} \mathrm{H}_{4}$ in samples to overcome the human toxicity issues caused by hydrazine, as the device fabricated using the $\mathrm{V}_{2} \mathrm{O}_{5}-\mathrm{CS}$ nanohybrid is fast, selective, and efficient. Hence, from this, it can be stated that a favorable electrochemical sensing device platform has been established for the determination of $\mathrm{N}_{2} \mathrm{H}_{4}$; but further studies are still needed to develop an on-site model for $\mathrm{N}_{2} \mathrm{H}_{4}$ detection in real samples, and our group is working towards achieving these objectives in the near future.

\section{Conflicts of interest}

The authors declare no conflict of interest for this work.

\section{Acknowledgements}

All the authors are thankful to their respective institutions. Furthermore, J.S. expresses gratitude for the DST-INSPIRE faculty Fellowship, BHU (IoE grant), and UGC New Delhi for financial support. K.RB.S. would like to express gratitude to Professor A. K. Singh for providing constant support and guidance throughout this work. R.P.S. is thankful to VC, IGNTU, Amarkantak, India, for providing constant support financially and for motivating us to do good science, and last, D.K. is thankful to the VC, DTU, Delhi, India.

\section{References}

1 R. Ahmad, N. Tripathy and Y.-B. Hahn, Chem. Commun., 2014, 50, 1890-1893.

2 S. D. Zelnick, D. R. Mattie and P. C. Stepaniak, Aviat., Space Environ. Med., 2003, 74, 1285-1291.

3 R. Maji, A. K. Mahapatra, K. Maiti, S. Mondal, S. S. Ali, P. Sahoo, S. Mandal, M. R. Uddin, S. Goswami and C. K. Quah, RSC Adv., 2016, 6, 70855-70862.

4 M. B. Gholivand and A. Azadbakht, Electrochim. Acta, 2011, 56, 10044-10054.

5 A. A. Ensafi and B. Rezaei, Talanta, 1998, 47, 645-649.

6 J. Mo, B. Ogorevc, X. Zhang and B. Pihlar, Electroanal. An Int. J. Devoted to Fundam. Pract. Asp. Electroanal., 2000, 12, 48-54.

7 K. Yamamoto and S. Kawanishi, J. Biol. Chem., 1991, 266, 1509-1515.

8 H. M. Moghaddam, H. Beitollahi, S. Tajik, I. Sheikhshoaie and P. Biparva, Environ. Monit. Assess., 2015, 187, 1-12.

9 U. P. Azad and V. Ganesan, Electrochim. Acta, 2011, 56, 5766-5770.

10 V. A. Maraldi, Master thesis, Universidade Estadual Paulista 'Júlio de Mesquita Filho', 2018, http://hdl.handle.net/11449/157120.

11 K. R. Singh, M. Fernandes, T. Sarkar and P. Sridevi, Infect. Non Infect. Dis., 2019, 4, 1-7.

12 P. Singh, K. R. Singh, J. Singh, S. N. Das and R. P. Singh, RSC Adv., 2021, 11, 18050-18060.

13 A. K. Yadav, T. K. Dhiman, G. B. V. S. Lakshmi, A. N. Berlina and P. R. Solanki, Int. J. Biol. Macromol., 2020, 151, 566-575.

14 X. Yue, W. Yang, M. Xu, X. Liu and J. Jia, Talanta, 2015, 144, 1296-1300.

15 M. K. Rofouei, H. Khoshsafar, H. Bagheri and R. J. Kalbasi, Int. J. Environ. Anal. Chem., 2018, 98, 156-170.

16 H. Rostami, F. Khosravi, M. Mohseni and A. A. Rostami, Int. J. Biol. Macromol., 2018, 107, 343-348.

17 J. Singh, A. Roychoudhury, M. Srivastava, P. R. Solanki, D. W. Lee, S. H. Lee and B. D. Malhotra, Nanoscale, 2014, 6, 1195-1208.

18 D. Grieshaber, R. MacKenzie, J. Vörös and E. Reimhult, Sensors, 2008, 8, 1400-1458.

19 P. R. Solanki, A. Kaushik, V. V. Agrawal and B. D. Malhotra, NPG Asia Mater., 2011, 3, 17-24. 
20 R. P. Singh, P. Singh and K. R. B. Singh, Composite Materials, CRC Press, Boca Raton, FL, 1st edn, 2021, pp. 1-28.

21 R. P. Singh, Int. J. Electrochem., 2011, 2011, 1-30.

22 R. P. Singh, in Nanotechnology, ed. R. Prasad, M. Kumar and V. Kumar, Springer Singapore, Singapore, 2017, pp. 293303.

23 R. P. Singh, Advances in Nanostructured Composites, CRC Press, Taylor \& Francis Group, Boca ERaton, FL, Series: A Science Publishers Book, 2019, vol. 1, pp. 16-47.

24 V. Nayak, K. R. Singh, A. K. Singh and R. P. Singh, New J. Chem., 2021, 45, 2849-2878.

25 K. R. Singh, V. Nayak, T. Sarkar and R. P. Singh, RSC Adv., 2020, 10, 27194-27214.

26 X. Liu, J. Zeng, H. Yang, K. Zhou and D. Pan, RSC Adv., 2018, 8, 4014-4031.

27 N. Asim, S. Radiman, M. A. Yarmo and M. S. B. Golriz, Microporous Mesoporous Mater., 2009, 120, 397-401.

28 L. Mai, F. Dong, X. Xu, Y. Luo, Q. An, Y. Zhao, J. Pan and J. Yang, Nano Lett., 2013, 13, 740-745.

29 M. Beaula Ruby Kamalam, S. S. R. Inbanathan, K. Sethuraman, A. Umar, H. Algadi, A. A. Ibrahim, Q. I. Rahman, C. S. Garoufalis and S. Baskoutas, Environ. Res., 2021, 199, 111369.

30 A. Baghban, M. Heidarizadeh, E. Doustkhah, S. Rostamnia and P. F. Rezaei, Int. J. Biol. Macromol., 2017, 103, 1194-1200.

31 E. Doustkhah, S. Rostamnia, B. Gholipour, B. Zeynizadeh, A. Baghban and R. Luque, Mol. Catal., 2017, 434, 7-15.

32 S. Kumar, J. Dutta, P. K. Dutta and J. Koh, Int. J. Biol. Macromol., 2020, 160, 470-481.

33 S. Kumar, A. Mukherjee and J. Dutta, Trends Food Sci. Technol., 2020, 97, 196-209.

34 M. Li, F. Kong, H. Wang and G. Li, CrystEngComm, 2011, 13, 5317-5320.

35 J. Singh, M. Srivastava, J. Dutta and P. K. Dutta, Int. J. Biol. Macromol., 2011, 48, 170-176.
36 L. Upadhyaya, J. Singh, V. Agarwal, A. C. Pandey, S. P. Verma, P. Das and R. P. Tewari, Process Biochem., 2015, 50, 678-688.

37 J. Singh and P. K. Dutta, Int. J. Biol. Macromol., 2009, 45, 384-392.

38 P. Meng and I. Ramli, Solid State Sci. Technol., 2007, 15, 128-133.

39 A. Kaushik, R. Khan, P. R. Solanki, P. Pandey, J. Alam, S. Ahmad and B. D. Malhotra, Biosens. Bioelectron., 2008, 24, 676-683.

40 C. Xiong, A. E. Aliev, B. Gnade and K. J. Balkus Jr., ACS Nano, 2008, 2, 293-301.

41 A. Pan, J.-G. Zhang, Z. Nie, G. Cao, B. W. Arey, G. Li, S. Liang and J. Liu, J. Mater. Chem., 2010, 20, 9193-9199.

42 L.-H. Li, J.-C. Deng, H.-R. Deng, Z.-L. Liu and L. Xin, Carbohydr. Res., 2010, 345, 994-998.

43 S. Kumar, N. Nigam, T. Ghosh, P. K. Dutta, S. P. Singh, P. K. Datta, L. An and T. F. Shi, Mater. Chem. Phys., 2010, 120, 361-370.

44 P. K. Rastogi, V. Ganesan and S. Krishnamoorthi, Electrochim. Acta, 2014, 125, 593-600.

45 S. Daemi, A. A. Ashkarran, A. Bahari and S. Ghasemi, Sens. Actuators, B, 2017, 245, 55-65.

46 J. Panchompoo, L. Aldous, C. Downing, A. Crossley and R. G. Compton, Electroanalysis, 2011, 23, 1568-1578.

47 S. Dutta, C. Ray, S. Mallick, S. Sarkar, A. Roy and T. Pal, RSC Adv., 2015, 5, 51690-51700.

48 R. Kumar, D. Rana, A. Umar, P. Sharma, S. Chauhan and M. S. Chauhan, Sens. Lett., 2014, 12, 1273-1278.

49 B. Šljukić, C. E. Banks, A. Crossley and R. G. Compton, Electroanalysis, 2006, 18, 1757-1762.

50 G. Vinodha, P. D. Shima and L. Cindrella, J. Mater. Sci., 2019, 54, 4073-4088.

51 P. B. Deroco, I. G. Melo, L. S. R. Silva, K. I. B. Eguiluz, G. R. Salazar-Banda and O. Fatibello-Filho, Sens. Actuators, $B, 2018,256,535-542$.

52 Z. Zhao, W. Wang, W. Tang, Y. Xie, Y. Li, J. Song, S. Zhuiykov, J. Hu and W. Gong, Ionics, 2020, 26, 2599-2609. 